\title{
Analysing the Correlation Between Secondary Mathematics Curriculum Change and Trends in Beginning Undergraduates' Performance of Basic Mathematical Skills in Ireland
}

\author{
Fiona Faulkner \\ Technological University Dublin, fiona.faulkner@tudublin.ie \\ P. Treacy \\ University of Derby \\ Mark Prendergast \\ Trinity College Dublin
}

Follow this and additional works at: https://arrow.tudublin.ie/ltcart

Part of the Higher Education Commons

\section{Recommended Citation}

Faulkner, F., Treacy, P. \& Prendergast, M. (2016). Analysing the correlation between secondary mathematics curriculum change and trends in beginning undergraduates' performance of basic mathematical skills in Ireland. Irish Educational Studies, vol. 35, no. 4. doi.org/10.1080/

03323315.2016 .1243067

This Article is brought to you for free and open access by the Learning Teaching \& Assessment at ARROW@TU Dublin. It has been accepted for inclusion in Articles by an authorized administrator of ARROW@TU Dublin. For more information, please contact arrow.admin@tudublin.ie, aisling.coyne@tudublin.ie, gerard.connolly@tudublin.ie.

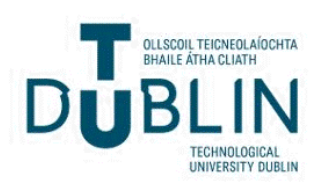




\title{
Analysing the correlation between secondary mathematics curriculum change and trends in beginning undergraduates' performance of basic mathematical skills in Ireland
}

\author{
Páraic Treacy (iD ${ }^{\mathrm{a} *}$, Fiona Faulkner ${ }^{\mathrm{b}}$ and Mark Prendergast (iD) ${ }^{\mathrm{c}}$ \\ ${ }^{a}$ College of Education, University of Derby, Derby, UK; ${ }^{b}$ Hospitality Management and Tourism \\ Department, Dublin Institute of Technology, Dublin, Ireland; ' $S$ School of Education, Trinity \\ College Dublin, Dublin, Ireland
}

(Received 28 July 2015; accepted 20 September 2016)

\begin{abstract}
The phenomenon in which students enter university under-prepared for the mathematical demands of their undergraduate courses, regularly referred to as the 'Maths Problem', has been widely reported in Ireland, UK, Australia, and the US. This issue has been of particular concern in Ireland recently, with beginning undergraduates' performance of basic mathematical skills showing signs of significant decline in recent years. New mathematics curricula, commonly referred to as 'Project Maths', were gradually introduced into the Irish secondary school education system from 2010 onwards. These new curricula aim to place greater emphasis on student understanding of mathematical concepts, use of contexts, and applications of mathematics. This study analyses, through mathematics diagnostic test data gathered between 2008 and 2014, the change in the basic mathematical skills of beginning undergraduates over the time period in which the new mathematics curricula were introduced to secondary education in Ireland. It was found that students' basic mathematical skills have declined over the time period during which the new mathematics curricula were introduced. Significant declines in beginning undergraduates' performance of basic mathematical skills were observed during the period 2008-2014, particularly among students who have achieved Higher Level $\mathrm{C}$ grades and Higher Level D grades.
\end{abstract}

Keywords: curriculum change; mathematical competencies; basic mathematical skills; mathematical under-preparedness; Project Maths

\section{Introduction}

The mathematical under-preparedness of students entering third level institutions in Ireland has been widely reported in recent years (Cleary 2007; Faulkner, Hannigan, and Gill 2010; Carr, Bowe, and Ní Fhloinn 2013; Treacy and Faulkner 2015). This phenomenon in which students are under-prepared for the mathematical demands of their undergraduate courses is regularly referred to as the 'Maths Problem' (Lawson, Croft, and Waller 2012). Commonly cited characteristics of this issue include a lack of basic mathematical skills, fragmented understanding, inadequate concept knowledge, and inability to successfully solve mathematical problems. The 'Maths Problem' has been highlighted as an issue of concern in Ireland, the UK,

\footnotetext{
*Corresponding author. Email: p.treacy@derby.ac.uk 
Australia, and the US (Lawson 2003; O’Donoghue 2004; Gill et al. 2010; Treacy and Faulkner 2015).

In addition to this documented decline in basic mathematical skills among beginning undergraduates, it has been reported that over four-fifths of school leavers in Ireland identified significant differences in approaches to teaching and learning between secondary level and further/higher education (Liston and O'Donoghue 2009; McCoy et al. 2014). Low retention rates in higher education STEM (Science, Technology, Engineering, and Mathematics) courses have been linked to students' shortcomings in mathematics (Bourn 2007) which would lead one to consider that these reported issues in mathematics education in Ireland are cause for concern.

In Ireland, steps have been taken to address deficiencies in secondary level students' mathematics capabilities. Junior Cycle (lower secondary level) and Senior Cycle (upper secondary level) mathematics curricula have been overhauled with the introduction of 'Project Maths'. The aim of these new curricula is to place greater emphasis on student understanding of mathematical concepts with increased use of contexts and applications of mathematics in real world scenarios. The new Project Maths curricula intend to encourage a greater focus on problem-solving skills and development of appreciation for the subject by placing mathematics in contexts familiar to students. Allied to that, assessment has been aligned with these intended revised classroom practices (NCCA 2008; DES 2010). Transformations in mathematics curricula of this nature have been attempted before in other nations with varying levels of success.

\section{A brief history of international mathematics curriculum change}

Significant shifts in the structure, content, and core principles of mathematics curricula have been ongoing in countries such as the US, China, Japan, and the Netherlands, among others, in varying periods since the middle of the twentieth century. The 'New Maths' movement, which focussed on structure, proof, generalisation, and abstraction, had dominated mathematics education in the US in the 1950s and 1960 s but ultimately failed due to the absence of comprehensive broad-based professional development for teachers, while the use of abstract mathematics at an elementary level was also major contributory factor to the downfall of the movement (Schoenfeld 2004; Woodward 2004).

'An Agenda for Action', published by the National Council of Teachers of Mathematics (NCTM) in 1980, called for a radical change to mathematics education in the US which would necessitate a move away from the emphasis which had been placed on skills and procedures - a lasting residue from the 'New Maths' movement. Once the core principles of 'An Agenda for Action' were adopted in the US, problem-solving became the focus of school mathematics, the widespread use of calculators was promoted, and there was de-emphasis of calculus (Schoenfeld 2004; Klein 2007). The 1989 'Curriculum and Evaluation Standards for School Mathematics' - commonly referred to as the 'Standards' - built on these recommendations by endorsing student-centred, discovery learning through real world problems. Mathematical skills and principles were to be learned through these problems rather than knowledge transfer; the drive for widespread introduction of calculators intensified; and mathematics for its own sake was not encouraged (Klein 2007). Social justice and the 
needs of business were often referred to as reasons for the adjustments (Schoenfeld 2004).

In the 1990s, virtually all American states adopted the principles of the 1989 Standards in their mathematics curriculum design and implementation (Schoenfeld 2004; Klein 2007). However, levels of acceptance of the new curricula varied between states with the result that implementation of this approach was fragmented in certain instances. For example, by 1997 California had rejected the 1989 Standards principles in favour of new standards which relied more on the traditional 'New Maths' (Klein 2007). Changes such as the No Child Left Behind Act in 2001 and increased levels of accountability prompted greater focus on standardised testing in mathematics with a de-emphasis of reasoning, representation, and problem-solving. However, the recent widespread adoption of Common Core State Standards in Mathematics would indicate that there may be a return to the focus on problem-solving and placing mathematics in context but that remains to be determined (Schoenfeld 2014).

In Japan and China, influences of Western countries, particularly the US, led to greater emphasis on problem-solving within their respective curricula. In 1989, Japan began to place mathematics problems in more familiar contexts in order to develop students' appreciation of mathematics and encourage its use in their daily lives (Koyama 2010). In a similar fashion in 2001, China reduced the emphasis on acquisition of knowledge and skills, instead focussing on the development of positive attitudes and linking content to student interests and experiences (Liu and Li 2010). The 1989 Standards proved to be a major influence as the core values of this document were adopted and adapted to a Chinese setting. This has brought about radical changes in curriculum, classroom, and teacher research cultures (Liu and Li 2010) resulting in the adoption of mathematics tasks which have increased in cognitive demand, use of multiple representations, and incidence of multiple solution methods when compared to tasks explored before the reform (Ni et al. 2014). Mathematics curricula continue to evolve in China but it would appear that the ideals which were heavily influenced by the 1989 Standards have persisted and been maintained (Liu and Li 2010; Ni et al. 2014).

This evolution of modern mathematics education towards an emphasis on problem-solving and the use of practical contexts can be largely traced back to the Netherlands. The Dutch mathematics education system managed to avoid becoming part of the 'New Maths' movement due to the establishment of the Wiskobas project in 1968 which acted as a precursor for Realistic Mathematics Education (RME) (Van den Heuvel-Panhuizen and Drijvers 2014). In 1970, the Freudenthal Institute in the Netherlands began to develop the curriculum model RME. This model uses imaginable contexts in which mathematics is placed so that students can make sense of what they are learning (Van den Heuvel-Panhuizen and Drijvers 2014). Freudenthal 'felt mathematics must be connected to reality, stay close to children's experience and be relevant to society, in order to be of human value' with students active and interactive within the learning process (Van den Heuvel-Panhuizen 2000, 3).

As the principles of RME have greatly influenced mathematics curricula in the Netherlands (Van den Heuvel-Panhuizen and Drijvers 2014), it is not out of order to suggest that this model has been a major factor in the consistently prolific performance of the Dutch students within the assessments carried out by The Programme for International Student Assessment (PISA). In 2012, the Netherlands ranked as one of the top European nations (10th out of 65 overall) in the PISA assessments, performing 
significantly above the average for participating nations (OECD 2014). The gradual shift in an international context, as outlined previously, towards the ideals of RME is also an indicator of the endorsement of these values in the wider mathematics education community.

Analysis of these instances of mathematics curricula changes in an international context led Schoenfeld $(2014,67)$ to conclude that 'within any one nation, one sees radical shifts over the course of time - often in contradictory directions'. The current transformation in second level mathematics curricula in Ireland is another example of this trend as the previous focus on procedural knowledge has been replaced with a renewed emphasis on problem-solving and placing mathematics in practical contexts. Oldham (2001) stated that the 'New Maths' curricular culture had, at that time, dominated Irish post-primary mathematics teaching for the previous 40 years. This remained the case until the transition to Project Maths which commenced in earnest in 2010.

Successfully implementing substantial mathematics curriculum change of this nature takes time, with impediments to this transformation regularly encountered (Handal and Herrington 2003; Schoenfeld 2014). It has been demonstrated that one of the key agents of mathematics curriculum change is the teachers, particularly their knowledge, status, and opportunities for professional development and career progression, as these factors greatly influence the application of new curricula (Liu and Li 2010; Schoenfeld 2014). Recognition of this phenomenon is evident in an Irish context.

\section{The initial stages of mathematics curriculum change in Ireland}

The introduction of new mathematics curricula at secondary level is not the only focus of change in Irish secondary mathematics education. Greater attention has also been placed on the qualifications of practicing secondary mathematics teachers in the country. In a 2009 study, it was determined that $48 \%$ of teachers in Ireland allocated to teach secondary level mathematics were not sufficiently qualified to do so (Ní Ríordáin and Hannigan 2011). These teachers were teaching a subject which did not match their training or education and were thus termed as being 'out of field'. The findings outlined in this report prompted the introduction of the Professional Diploma in Mathematics for Teaching so that these teachers could upskill and ensure they became fully qualified to teach mathematics at secondary level in Ireland. This 2year part-time blended learning programme was implemented nationwide in 2012. The first two cohorts, consisting of approximately 300 teachers in each, graduated in January 2015 and January 2016 while two further cohorts are working towards this goal at present.

The National Council for Curriculum and Assessment (NCCA) in Ireland have also outlined recommendations to support teachers during this period of curriculum change through continuing professional development (CPD). During the initial stages in which the new Project Maths syllabus was introduced, CPD was provided for secondary level mathematics teachers on a national level. The conclusion of this provision prompted the NCCA (2014) to recommend establishment of further online support materials for teachers and also recommended that structures be put in place to facilitate practicing mathematics teachers to achieve mathematics pedagogy-focussed post-graduate qualifications, ideally at Masters level. 
Mathematics performance in secondary education is the strongest predictor of successful student progression through tertiary level education in Ireland (Mooney et al. 2010) as well as tertiary level mathematics (Faulkner, Hannigan, and Fitzmaurice 2014). Similarly, it has been proven to play an important role in a country's economic growth and well-being (OECD 2010). Thus, the aforementioned focus on improving the quality of teaching and learning within the subject is imperative. The effects of these efforts on student performance in mathematics are likely to be of great national and international interest over the coming years. This study aims to offer early indications of some elements of these effects, particularly the effects on student performance of basic mathematical skills as they transition from secondary to tertiary education.

The findings outlined in this paper will track changes in beginning undergraduate students' mathematics competencies in specific topics between 2008 and 2014. The means by which these students' performances of basic mathematical skills were determined - the University of Limerick (UL) mathematics diagnostic test - will be outlined along with a general profile of the students' mathematical backgrounds. Furthermore, a detailed analysis of the trends related to student performance on the UL mathematics diagnostic test will be tracked and discussed in detail.

\section{Mathematical background of beginning undergraduates in Ireland}

The vast majority of students who leave secondary level education to enter tertiary level education in Ireland have studied mathematics throughout their time in secondary school (SEC 2014). Mathematics is one of three compulsory subjects in the Leaving Certificate examinations - the final examinations for students at secondary level. Typically at age 17 or 18 , students sit the Leaving Certificate mathematics examination at one of three levels - Higher, Ordinary, or Foundation. Changes in how these students have been assessed in mathematics at Leaving Certificate have occurred since 2012 with the introduction of Project Maths. This curriculum was gradually phased in to the Senior Cycle - the final two years of secondary level education - in all Irish secondary schools, starting in September 2010 (DES 2010). Elements of the Project Maths syllabus were thus incorporated into the Leaving Certificate mathematics examinations in June 2012, with gradually more added in June 2013. The first examination to be completely based on the new curriculum in all Irish secondary schools took place in June 2014.

This timeline was important when determining the data to explore within this research. The years 2008-2014 were selected so that a pattern could be observed in the years before the phased introduction of the new curriculum, as well as the years in which the new curriculum was gradually introduced, and the first year (2014) in which the new curriculum was fully implemented within the Leaving Certificate examinations. In November 2013, an early assessment of the impact of Project Maths was published which concluded that there did not appear to be any link between the new curriculum and any overall decline or progression in students' achievement in mathematics (Jeffes et al. 2013). The analysis outlined in this paper will examine these claims and provide further evidence of the initial effects this curriculum change has had on student performance of basic mathematical skills in specific topics.

The importance of the effects of this change in curriculum can be linked, among other factors, to the fact that results in the Leaving Certificate examinations determine 
whether or not a student transitions directly from secondary education to their chosen course of study at tertiary level in Ireland. Points are awarded to students based on the grades achieved in the Leaving Certificate examinations (see Table 1). The number of points achieved by a student is a major factor in determining courses to which the student may gain entry in third level education. To boost the numbers of students opting to study mathematics at Higher Level for the Leaving Certificate, 25 bonus points were awarded to students who achieved a grade D3 or above in the Higher Level Leaving Certificate mathematics examination. This measure, introduced in 2012, has had a noticeable effect on the proportion of students opting to study Higher Level mathematics at Leaving Certificate. The proportion of students opting for the Higher Level mathematics paper at Leaving Certificate increased from $15.8 \%$ in 2011 to $22.1 \%$ in $2012 ; 25.6 \%$ in 2013; and $27 \%$ in 2014 (SEC 2014). The impact of this reported increase will be discussed in greater detail later in this article.

\section{The UL diagnostic test and methodology}

Students entering first year service mathematics modules for science-based and technology-based undergraduate degree courses at UL have been given a 40-question mathematics diagnostic test (see sample questions in Appendix 1) without prior notification during their first assigned lecture each year since 1998. This test aims to assess the performance of basic mathematical skills in selected mathematical topics. These topics can be broadly grouped as arithmetic (13 questions), algebra (8 questions), geometry (11 questions), calculus (7 questions), and modelling (1 question).

Of the 40 questions, 34 were set at a Leaving Certificate Ordinary Level standard or below when the test was developed in 1997 by Prof. John O'Donoghue of the UL Department of Mathematics \& Statistics. The remaining six questions were set at a Leaving Certificate Higher Level standard. Students who score 18/40 or less in this diagnostic test are considered to be under-prepared for the mathematical demands of their service mathematics module, thus they are deemed to be 'at risk'. Research by Faulkner (2012) objectively proved that setting this as the cut-off point for determining whether or not a student is 'at risk' would be an accurate prediction of their

Table 1. Points awarded for grades achieved in Leaving Certificate examinations. Note: HA1 represents an A1 grade at Higher Level; OB3 represents a B3 grade at Ordinary Level.

\begin{tabular}{lccc}
\hline Grade & Points & Grade & Points \\
\hline HA1 & 100 & OA1 & 60 \\
HA2 & 90 & OA2 & 50 \\
HB1 & 85 & OB1 & 45 \\
HB2 & 80 & OB2 & 40 \\
HB3 & 75 & OB3 & 35 \\
HC1 & 70 & OC1 & 30 \\
HC2 & 65 & OC2 & 25 \\
HC3 & 60 & OC3 & 20 \\
HD1 & 55 & OD1 & 15 \\
HD2 & OD2 & 10 \\
HD3 & 50 & OD3 & 5 \\
\hline
\end{tabular}


likely performance based on retrospective data. This conclusion was largely informed by the finding that, in the period $1998-2008,84.4 \%$ of students who achieved a mark of 18 or less in the UL diagnostic test went on to fail their end-of-term examination. Students who are termed 'at risk' are encouraged to avail of mathematics support services available at UL in a timely and regular manner to address any gaps in their mathematical knowledge and skills.

The design of the UL diagnostic test was carried out through analysis and adjustment of an initial list of 70 questions by a team of experienced service mathematics lecturers. These lecturers reduced this set of 70 questions to the final 40 question version used from 1997 to the present day. The questions are set to specifically match the mathematical level required of students in the targeted UL service mathematics modules. The UL diagnostic test was piloted in Irish secondary schools and compared with the European Society for Engineering Education (SEFI) Core Level Zero syllabus for engineers, the Irish Junior Certificate mathematics syllabus, the Irish Leaving Certificate mathematics syllabus, and further diagnostic tests to ensure validity of this research tool (Gill et al. 2010).

Achieving internal consistency within a diagnostic test of this nature would ensure that all items on this test measure the same construct. However, in this case, the UL diagnostic test was aiming to replicate the types of questions on the Leaving Certificate examinations when it was developed in 1997 and not measure one single construct. As a result, internal consistency may have been sacrificed somewhat in an effort to ensure the UL diagnostic test contained a spread of questions in the correct proportions which represented the type of mathematical skills students were expected to master in Leaving Certificate mathematics examinations at the time.

The UL diagnostic test places greater focus on the measure of computational skills rather than problem-solving skills as this mirrored the focus of Leaving Certificate mathematics up until the introduction of the new Project Maths curricula. Although the test instrument now no longer matches Leaving Certificate mathematics as accurately, maintaining the same test questions allows for consistency in the comparisons of students' basic mathematical skills across year groups regardless of the similarities it has to the current curriculum. It must also be noted that all content examined through the UL diagnostic test continues to be part of the Project Maths curricula at Senior Cycle. As such, these basic skills would be required to successfully answer questions posed in Leaving Certificate mathematics examinations.

Each year between 1998 and 2014, information regarding the UL diagnostic test was gathered and recorded for each student in the UL database. This student information included, among other information, their gender, undergraduate course, Leaving Certificate mathematics examination grade, and whether or not they had answered each of the 40 UL diagnostic test questions correctly. The UL database, which contains data from these diagnostic tests, currently holds information on over 10,700 students. The same diagnostic test was used in each of these years to ensure that direct comparisons in basic mathematical competency levels can be reliably made. Conditions for the test were kept consistent - each test was completed in lecture halls and the duration of the test was 45 minutes. Students were not provided with advance notice of the test or the content by UL academic staff but it is possible that they may have been informed of the test by students outside their cohort that had completed the test themselves as beginning undergraduates in previous years. 
The use of calculators was not permitted during the UL diagnostic test in any given year. Such a measure was taken in order to properly test whether students understood how to successfully complete basic algorithms and procedures, for example, subtracting one fraction from another; following the order of operations; or implementing the laws of logarithms appropriately. If the use of calculators was permitted during the UL diagnostic test then students could possibly obtain the correct answer without understanding how they arrived at that answer. Thus, removing the option of using a calculator ensures students must apply the required understanding to answer such questions correctly.

The proportion of beginning undergraduates in these service mathematics modules that attempted the UL diagnostic test tended to fluctuate in the period 2008-2014 (between $80.4 \%$ and $92.7 \%$ ) as the test was not compulsory nor did it affect their course credit. In order to accommodate this, the authors focussed the majority of their analysis on statistics and trends in which student performance in the UL diagnostic test was grouped according to their performance in the Leaving Certificate mathematics examinations. This ensured that changes in the Leaving Certificate mathematics grade profile of each yearly cohort that completed the UL diagnostic test would not impact upon key analysis within this study.

The fact that the test was not compulsory may limit the effort students put into completing the questions. Similarly, the lack of warning given that they would be completing such a test negates any opportunities for preparation and thus may have hindered students' performance. However, these two limitations were a consistent factor each year as students were reminded that the test outcome would not affect their grade each time the test was administered and notification prior to the test was never given. Thus, comparisons made between performances in any given year should not be affected by these factors.

This paper will focus on data from 2008 to 2014 so that clear trends in the period before, during, and just after the phased introduction of the Project Maths curriculum to the Leaving Certificate mathematics examinations can be observed and analysed.

\section{Research questions and hypothesis}

Analysis of the data from the UL database was carried out in an attempt to aid the authors in answering the following research questions:

- What are the trends in basic mathematical competency levels of beginning undergraduates in each of the diagnostic test topics in the period 2008-2014?

- Are there noteworthy changes in basic mathematical competency levels which can be aligned with the changes to the mathematics curriculum at second level in the period 2008-2014?

- Is there any evidence of grade dilution in Leaving Certificate mathematics in the period 2008-2014?

The authors hypothesised that basic mathematical competency levels would show a decline in most of the diagnostic test topics during the period 2008-2014. Previous research informed this hypothesis as it was determined that the execution of basic mathematical skills by beginning undergraduates in the UL database was in decline in the period 1998-2008 (Faulkner, Hannigan, and Fitzmaurice 2014) and the 
period 2003-2013 (Treacy and Faulkner 2015). The authors anticipated that evidence of grade dilution would be present between 2008 and 2014 as there are indicators in their previous research that such an issue was emerging during the phased introduction of the Project Maths syllabus (Treacy and Faulkner 2015).

\section{Mathematical background of students in the UL database}

In order to comprehensively answer the research questions outlined in the previous section, the mathematical background of the students who completed the UL diagnostic test must be outlined in detail.

\section{Proportion of students with higher level and ordinary level leaving certificate backgrounds 2008-2014}

Analysis of the achievements in Leaving Certificate mathematics will give an insight into the typical profile of students entering service mathematics modules at UL. The majority of students who completed the diagnostic test from 2008 to 2013 had studied mathematics at Ordinary Level in the Leaving Certificate (between 50.4\% and $60.8 \%$ ). From 2012 onwards, the proportion of beginning undergraduates who had studied at Ordinary Level at Leaving Certificate began to fall while the proportion of students who had studied mathematics at Higher Level for the Leaving Certificate started to rise (see Figure 1). By 2014, the proportion of beginning undergraduate students with a Higher Level Leaving Certificate mathematics background (51.2\%) was greater than the proportion of students with an Ordinary Level Leaving Certificate background (43\%) (see Figure 1).

This significant change may be explained in part by the offer of 25 bonus points in the Leaving Certificate for students who obtain a grade D3 or higher in the Higher Level mathematics examination. This initiative commenced in 2012 and has been retained each year since, with no indication that the measure will be discontinued. Since the introduction of these bonus points, there has been a noticeable increase in the proportion of students opting for Higher Level mathematics at Leaving Certificate in

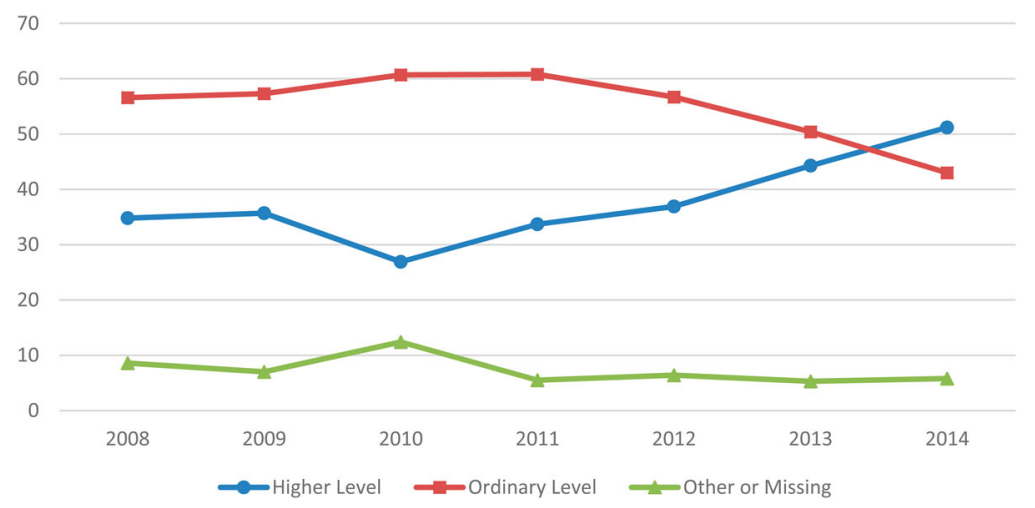

Figure 1. Proportion of students that completed the UL diagnostic test and entered UL service mathematics modules from Leaving Certificate Higher Level, Leaving Certificate Ordinary Level or other (2008-2014). 
Ireland, rising from $15.8 \%$ in 2011 to $22.1 \%$ in $2012,25.6 \%$ in 2013 and $27 \%$ in 2014 (SEC 2014). This change has been reflected in the data recorded in the UL database.

Students who either completed their secondary level studies outside Ireland, did not sit their Leaving Certificate in the previous 10 years, or did not sit a Leaving Certificate mathematics examination at all were termed as 'Other/Missing' in the database. These students typically accounted for a small percentage of each cohort, that is, between $2.4 \%$ and $12.4 \%$, with no pattern of note to this variation.

\section{Proportion of students achieving each grade in leaving certificate mathematics 2008- 2014}

Analysis of students' performance in mathematics at Leaving Certificate (see Figure 2) would indicate that students have achieved a similar spread of grades in Leaving Certificate examinations in the timeframe explored (2008-2014). There are, however, some differences in the years 2012, 2013, and 2014 when compared to the years previous as the proportion of students achieving Ordinary Level A grades (OA) declined while the proportion of those achieving Higher Level C grades (HC) and Higher Level D grades (HD) increased in each of the years from 2012 to 2014. This change could be partially explained by the introduction of bonus points during that period - those that typically would have been expected to achieve Ordinary Level A grades in 2012, 2013, and 2014 may have opted to study Leaving Certificate mathematics at Higher Level in an attempt to take advantage of the bonus points on offer. Subsequently, these students may then have achieved Higher Level C or D grades.

\section{Results}

This section will present the important results relevant to the research questions outlined previously using data from the UL database collected between 2008 and 2014.

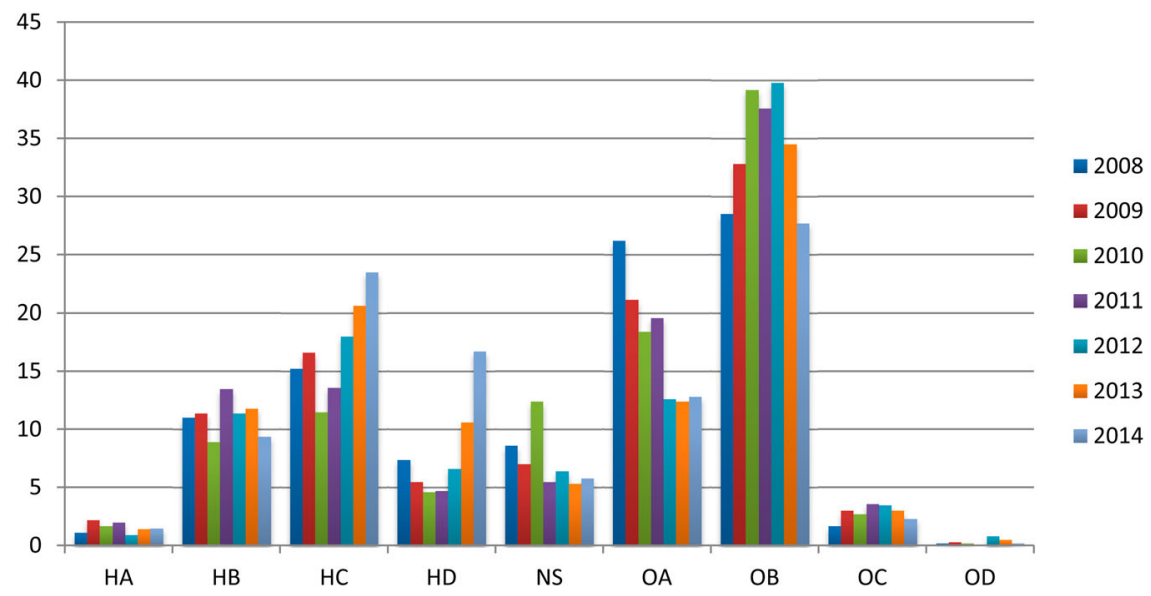

Figure 2. Percentage of students who completed the UL diagnostic test that achieved specific Leaving Certificate mathematics grades (2008-2014). 


\section{Proportion of students considered to be 'at risk' of failing their service mathematics module}

Treacy and Faulkner (2015) reported on the proportion of students assessed through the UL diagnostic test who were deemed to be 'at risk' of failing their service mathematics final exam within the period 2003-2013. They reported a significant increase in the proportion of 'at risk' students in that period: from $30.6 \%$ in 2003 and $25.6 \%$ in 2004 to $53.7 \%$ in 2012 and $48.7 \%$ in 2013. Similar proportions of 'at risk' students have been observed in the 2014 cohort, with a figure of $48.6 \%$ recorded (see Figure 3 ). In the period 2008-2011, the proportion of students at risk was between $40.6 \%$ and $46.1 \%$. After the introduction of bonus points, 2012 onwards, the proportion of students designated 'at risk' upon completing the UL diagnostic test increased with recordings of between $48.6 \%$ and $53.7 \%$. Therefore, an increase in the proportion of students studying Higher Level mathematics at Leaving Certificate over this time period has coincided with a decrease in overall performance by students in the UL diagnostic test (see Figures 2 and 3).

\section{Performance of students in each diagnostic test topic 2008-2014}

To investigate this increase in 'at risk' beginning undergraduates more closely, the performance of students overall and also within each of the 5 mathematics topics of the UL diagnostic test was analysed during this study. When students' mean scores in arithmetic, algebra, and calculus are compared for the years 2008 and 2014, a significant decline $(p<.05)$ is observed. These findings may provide some insight into the effects the introduction of Project Maths has had on beginning undergraduates' performance of basic mathematical skills in each of these topics. As observed previously, the spread of Leaving Certificate mathematics grades of students from the 2008 cohort is noticeably different from students in the 2014 cohort (see Figure 2). It is therefore necessary to examine students' overall performance and their performance in each

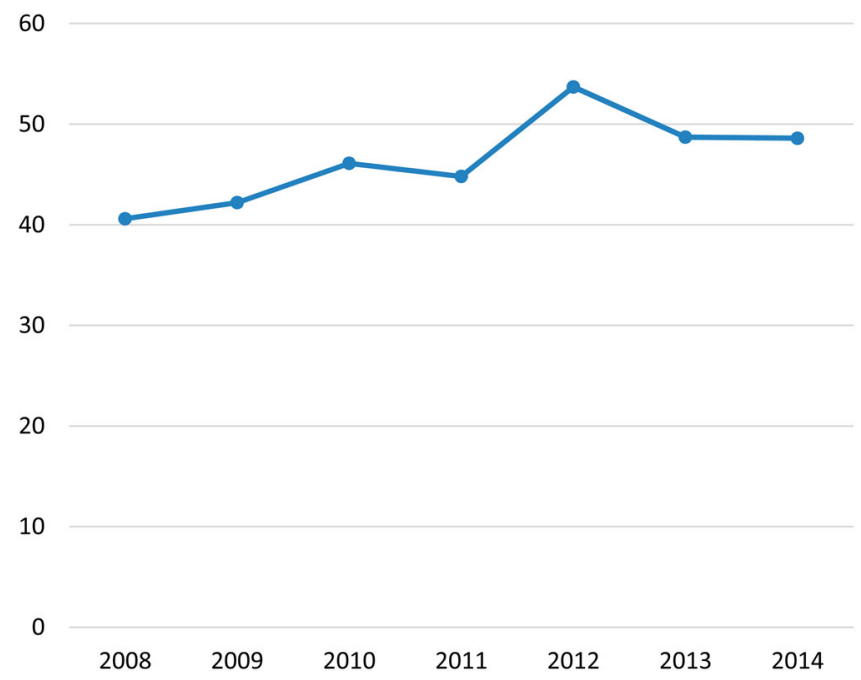

Figure 3. Percentage of students who completed the UL diagnostic test that scored 18/40 or less in the UL diagnostic test. 
topic on the UL diagnostic test according to the Leaving Certificate grade achieved. This analysis will be outlined in the next section.

\section{Performance in each topic on the UL diagnostic test per leaving certificate mathematics grade}

The grades which will be considered will be Higher Level B, C, and D grades. The number of students in the database with Higher Level A grades was not sufficient to carry out reliable statistical analysis thus it will not be outlined here. It was also clear from early analysis that, even though there has been a noted increase in the proportions of students in the UL database who have achieved Higher Level B, C, and D grades in recent years, the proportion of students 'at risk' has increased noticeably in that period. This anomaly encouraged the authors to explore in greater depth the data of students who had achieved these grades.

The consistency of overall performance in the UL diagnostic test during the transition to the new Project Maths curriculum at Leaving Certificate varies significantly when performances in this test are analysed according to the Leaving Certificate grade achieved previously (see Table 2). Performance in the UL diagnostic test by students who had achieved a Higher Level B grade in Leaving Certificate mathematics in 2014 was found not to have changed significantly when compared to the 2008 cohort. In contrast, comparison of 2008 and 2014 data for students who achieved a Higher Level $\mathrm{C}$ grade at Leaving Certificate indicated a significant decline $(p<.001)$ in mean performance in the UL diagnostic test. A significant decline $(p<.001)$ was also present when a similar comparison of 2008 and 2014 data was made for those that achieved a Higher Level D grade at Leaving Certificate.

Students who achieved Leaving Certificate Higher Level B grades in the 2008 cohort performed similarly in most topics to those who achieved Leaving Certificate Higher Level B grades in the 2014 cohort (see Table 3). Significant changes ( $p$ $<.05$ ) were observed in two topics with improvement occurring in modelling, and a decline in performance noted in calculus. Comparison of 2009 and 2014 data for students who achieved a Higher Level B grade at Leaving Certificate indicated significant declines $(p<.05)$ in beginning undergraduates' performances in algebra and calculus.

Table 2. Mean performance (standard deviation) in the UL diagnostic test of beginning undergraduates who achieved Leaving Certificate mathematics Higher Level B, C, and D grades from 2008 to 2014. Values are scores out of 40.

\begin{tabular}{lcccccccc}
\hline & 2008 & 2009 & 2010 & 2011 & 2012 & 2013 & 2014 \\
\hline Higher Level B & $\mathbf{2 8 . 0}$ & 29.0 & 29.7 & 28.1 & 26.7 & 27.1 & 27.1 \\
& $(4.9)$ & $(4.5)$ & $(3.9)$ & $(5.1)$ & $(4.3)$ & $(4.2)$ & $(4.4)$ \\
& $n=60$ & $n=78$ & $n=58$ & $n=92$ & $n=84$ & $n=76$ & $n=60$ \\
Higher Level C & 25.5 & 25.4 & 24.5 & 24.7 & 22.5 & 23.4 & 22.8 \\
& $(5.5)$ & $(4.6)$ & $(4.9)$ & $(4.1)$ & $(4.1)$ & $(4.0)$ & $(4.4)$ \\
& $n=83$ & $n=113$ & $n=74$ & $n=93$ & $n=133$ & $n=133$ & $n=149$ \\
Higher Level D & $\mathbf{2 4 . 2}$ & $\mathbf{2 2 . 4}$ & $\mathbf{2 4 . 2}$ & $\mathbf{2 2 . 7}$ & 19.0 & 19.2 & 19.0 \\
& $(4.2)$ & $(4.7)$ & $(5.4)$ & $(4.9)$ & $(4.3)$ & $(3.8)$ & $(4.3)$ \\
& $n=40$ & $n=37$ & $n=30$ & $n=32$ & $n=49$ & $n=68$ & $n=106$ \\
\hline
\end{tabular}


Table 3. Mean performance (standard deviation) in each of the UL diagnostic test topics of beginning undergraduates who achieved Higher Level Leaving Certificate mathematics B grades from 2008 to 2014. Values are percentage scores.

\begin{tabular}{|c|c|c|c|c|c|c|c|}
\hline & $\begin{array}{c}2008 \\
n=60\end{array}$ & $\begin{array}{c}2009 \\
n=78\end{array}$ & $\begin{array}{c}2010 \\
n=58\end{array}$ & $\begin{array}{c}2011 \\
n=92\end{array}$ & $\begin{array}{c}2012 \\
n=84\end{array}$ & $\begin{array}{c}2013 \\
n=76\end{array}$ & $\begin{array}{c}2014 \\
n=60\end{array}$ \\
\hline Arithmetic & $\begin{array}{c}69.4 \\
(13.3)\end{array}$ & $\begin{array}{c}72.7 \\
(13.6)\end{array}$ & $\begin{array}{c}73.9 \\
(10.1)\end{array}$ & $\begin{array}{c}69.6 \\
(15.2)\end{array}$ & $\begin{array}{c}67.1 \\
(13.4)\end{array}$ & $\begin{array}{c}68.7 \\
(12.7)\end{array}$ & $\begin{array}{c}68.6 \\
(13.0)\end{array}$ \\
\hline Algebra & $\begin{array}{c}80.8 \\
(15.9)\end{array}$ & $\begin{array}{c}81.4 \\
(13.9)\end{array}$ & $\begin{array}{c}85.8 \\
(10.8)\end{array}$ & $\begin{array}{c}80.4 \\
(14.5)\end{array}$ & $\begin{array}{c}73.1 \\
(16.3)\end{array}$ & $\begin{array}{c}76.2 \\
(13.9)\end{array}$ & $\begin{array}{c}75.6 \\
(17.4)\end{array}$ \\
\hline Geometry & $\begin{array}{c}68.6 \\
(16.0)\end{array}$ & $\begin{array}{c}73.5 \\
(15.8)\end{array}$ & $\begin{array}{c}74.6 \\
(15.2)\end{array}$ & $\begin{array}{c}69.3 \\
(16.6)\end{array}$ & $\begin{array}{c}71.3 \\
(15.4)\end{array}$ & $\begin{array}{c}70.5 \\
(14.2)\end{array}$ & $\begin{array}{c}72.7 \\
(13.3)\end{array}$ \\
\hline Calculus & $\begin{array}{c}59.0 \\
(26.6)\end{array}$ & $\begin{array}{c}58.4 \\
(26.7)\end{array}$ & $\begin{array}{c}61.6 \\
(23.8)\end{array}$ & $\begin{array}{c}61.5 \\
(25.6)\end{array}$ & $\begin{array}{c}49.3 \\
(22.7)\end{array}$ & $\begin{array}{c}50.2 \\
(24.4)\end{array}$ & $\begin{array}{c}45.5 \\
(27.4)\end{array}$ \\
\hline Modelling & $\begin{array}{c}78.3 \\
(41.6)\end{array}$ & $\begin{array}{c}88.5 \\
(32.2)\end{array}$ & $\begin{array}{c}72.4 \\
(45.1)\end{array}$ & $\begin{array}{c}70.7 \\
(45.8)\end{array}$ & $\begin{array}{c}83.3 \\
(37.5)\end{array}$ & $\begin{array}{c}85.5 \\
(35.4)\end{array}$ & $\begin{array}{c}93.3 \\
(25.2)\end{array}$ \\
\hline
\end{tabular}

Comparison of students who achieved Higher Level C grades in Leaving Certificate mathematics in 2008 and 2014 also demonstrated significant declines, some more extreme than others. Significant declines $(p<.05)$ in performance are evident in four of the five topics: geometry, arithmetic, algebra, and calculus. The latter three of these topics displayed declines in mean performance by students in 2014 which were of notable significance $(p<.001)$ when compared to 2008 at this grade level. Comparing the performances of the 2009 cohort to the 2014 cohort also highlights significant declines $(p<.01)$ in mean performance of arithmetic, algebra, and calculus at this grade level (see Table 4).

When mean performance in the specific topics of the UL diagnostic test of students who achieved Higher Level D grades in the Leaving Certificate are compared for 2008 and 2014, significant declines $(p<.01)$ are found in four of the five topics (see Table 5). These topics are arithmetic, algebra, geometry, and calculus. Similar comparisons for

Table 4. Mean performance (standard deviation) in each of the UL diagnostic test topics of beginning undergraduates who achieved Higher Level Leaving Certificate mathematics $\mathrm{C}$ grades from 2008 to 2014. Values are percentage scores.

\begin{tabular}{lcccccccc}
\hline & 2008 & 2009 & 2010 & 2011 & 2012 & 2013 & 2014 \\
& $n=83$ & $n=113$ & $n=74$ & $n=93$ & $n=133$ & $n=133$ & $n=149$ \\
\hline Arithmetic & $\mathbf{6 3 . 6}$ & $\mathbf{6 5 . 2}$ & $\mathbf{6 1 . 9}$ & $\mathbf{6 4 . 0}$ & $\mathbf{5 5 . 5}$ & $\mathbf{6 1 . 0}$ & $\mathbf{5 7 . 4}$ \\
& $\mathbf{( 1 3 . 9 )}$ & $\mathbf{( 1 2 . 8 )}$ & $\mathbf{( 1 5 . 5 )}$ & $\mathbf{( 1 4 . 3 )}$ & $\mathbf{( 1 2 . 8 )}$ & $\mathbf{( 1 2 . 2 )}$ & $\mathbf{( 1 4 . 1 )}$ \\
Algebra & 73.3 & 74.3 & 74.5 & 73.0 & 69.2 & 67.8 & 65.5 \\
& $(18.2)$ & $(16.2)$ & $(21.0)$ & $(14.7)$ & $(16.3)$ & $(17.6)$ & $(18.8)$ \\
Geometry & $\mathbf{6 5 . 2}$ & $\mathbf{6 3 . 7}$ & $\mathbf{6 2 . 4}$ & $\mathbf{6 0 . 4}$ & $\mathbf{5 9 . 3}$ & $\mathbf{6 2 . 1}$ & $\mathbf{6 0 . 7}$ \\
& $\mathbf{( 1 6 . 7 )}$ & $\mathbf{( 1 7 . 1 )}$ & $\mathbf{( 1 6 . 2 )}$ & $\mathbf{( 1 3 . 2 )}$ & $\mathbf{( 1 4 . 6 )}$ & $\mathbf{( 1 4 . 2 )}$ & $\mathbf{( 1 5 . 0 )}$ \\
Calculus & 48.9 & 46.5 & 42.7 & 46.2 & 37.6 & 35.6 & 37.0 \\
& $(25.4)$ & $(23.0)$ & $(26.5)$ & $(26.4)$ & $(20.7)$ & $(21.1)$ & $(21.1)$ \\
Modelling & $\mathbf{7 4 . 7}$ & $\mathbf{7 4 . 3}$ & $\mathbf{6 4 . 9}$ & $\mathbf{7 3 . 1}$ & $\mathbf{6 0 . 9}$ & $\mathbf{7 2 . 9}$ & $\mathbf{8 2 . 6}$ \\
& $\mathbf{( 4 3 . 7 )}$ & $\mathbf{( 4 3 . 9 )}$ & $\mathbf{( 4 8 . 1 )}$ & $\mathbf{( 4 4 . 6 )}$ & $\mathbf{( 4 9 . 0 )}$ & $\mathbf{( 4 4 . 6 )}$ & $\mathbf{( 3 8 . 1 )}$ \\
\hline
\end{tabular}


Table 5. Mean performance (standard deviation) in each of the UL diagnostic test topics of beginning undergraduates who achieved Higher Level Leaving Certificate mathematics D grades from 2008 to 2014 . Values are percentage scores.

\begin{tabular}{|c|c|c|c|c|c|c|c|}
\hline & $\begin{array}{c}2008 \\
n=40\end{array}$ & $\begin{array}{c}2009 \\
n=37\end{array}$ & $\begin{array}{c}2010 \\
n=30\end{array}$ & $\begin{array}{c}2011 \\
n=32\end{array}$ & $\begin{array}{c}2012 \\
n=49\end{array}$ & $\begin{array}{c}2013 \\
n=68\end{array}$ & $\begin{array}{c}2014 \\
n=106\end{array}$ \\
\hline Arithmetic & $\begin{array}{c}61.2 \\
(17.0)\end{array}$ & $\begin{array}{c}60.1 \\
(12.5)\end{array}$ & $\begin{array}{c}58.5 \\
(14.5)\end{array}$ & $\begin{array}{c}58.9 \\
(13.3)\end{array}$ & $\begin{array}{c}50.9 \\
(15.5)\end{array}$ & $\begin{array}{c}50.6 \\
(14.9)\end{array}$ & $\begin{array}{c}49.5 \\
(14.8)\end{array}$ \\
\hline Algebra & $\begin{array}{c}70.6 \\
(16.4)\end{array}$ & $\begin{array}{c}64.5 \\
(14.9)\end{array}$ & $\begin{array}{c}74.2 \\
(19.7)\end{array}$ & $\begin{array}{c}73.4 \\
(14.5)\end{array}$ & $\begin{array}{c}56.1 \\
(16.8)\end{array}$ & $\begin{array}{c}54.4 \\
(18.0)\end{array}$ & $\begin{array}{c}54.4 \\
(20.6)\end{array}$ \\
\hline Geometry & $\begin{array}{c}64.8 \\
(13.1)\end{array}$ & $\begin{array}{c}58.7 \\
(14.9)\end{array}$ & $\begin{array}{c}61.8 \\
(19.0)\end{array}$ & $\begin{array}{c}56.0 \\
(17.6)\end{array}$ & $\begin{array}{c}51.4 \\
(13.9)\end{array}$ & $\begin{array}{c}54.7 \\
(12.8)\end{array}$ & $\begin{array}{c}52.1 \\
(13.8)\end{array}$ \\
\hline Calculus & $\begin{array}{c}37.9 \\
(19.6)\end{array}$ & $\begin{array}{c}32.4 \\
(26.4)\end{array}$ & $\begin{array}{c}47.1 \\
(23.2)\end{array}$ & $\begin{array}{c}33.5 \\
(25.8)\end{array}$ & $\begin{array}{c}24.2 \\
(19.4)\end{array}$ & $\begin{array}{c}23.7 \\
(16.7)\end{array}$ & $\begin{array}{c}25.5 \\
(15.4)\end{array}$ \\
\hline Modelling & $\begin{array}{c}80.0 \\
(40.5)\end{array}$ & $\begin{array}{c}73.0 \\
(45.0)\end{array}$ & $\begin{array}{c}53.3 \\
(50.7)\end{array}$ & $\begin{array}{c}62.5 \\
(49.2)\end{array}$ & $\begin{array}{c}55.1 \\
(50.3)\end{array}$ & $\begin{array}{c}58.8 \\
(49.6)\end{array}$ & $\begin{array}{c}67.9 \\
(46.9)\end{array}$ \\
\hline
\end{tabular}

the years 2009 and 2014 produce significant declines $(p<.05)$ in the same topics except for Calculus ( $p=.055$ ) which was marginally outside the cut-off point. It is noteworthy that there is no UL diagnostic test topic in which performance has increased significantly for students with a Higher Level Leaving Certificate mathematics $\mathrm{C}$ grade or D grade when 2008 data is compared to 2014 data (see Table 6).

\section{Discussion}

The comparisons drawn previously (see Results section) between mean scores within each individual mathematical topic by students who achieved Higher Level Leaving Certificate B, C, or D grades highlight declines in basic mathematical skills of students who achieve those grades. Significant declines in mean performance between 2008 and 2014 for arithmetic, algebra, geometry, and calculus at both Higher Level C and D grades (see Table 6) indicate that the basic skills inherent in these topics are in significant decline amongst students entering university with these Leaving Certificate mathematics grades. The significance of this observation is further increased when one considers that students entering UL service mathematics modules with particular

Table 6. Summary of statistically significant changes in beginning undergraduates' mean performance of basic mathematical skills by topic and by Leaving Certificate grade achieved.

\begin{tabular}{lccc}
\hline UL Diagnostic Test Topic & Higher Level B & Higher Level C & Higher Level D \\
\hline Arithmetic & & - & - \\
Algebra & - & - & - \\
Geometry & - & - & - \\
Calculus & + & & - \\
Modelling & & \\
\hline
\end{tabular}

$+=$ Significant increase $(p<.05)$ in performance when data from 2008 to 2014 are compared.

$-=$ Significant decline $(p<.05)$ in performance when data from 2008 to 2014 are compared. 
Leaving Certificate mathematics grades performed to a similar level in the diagnostic test between 1998 and 2008 (Faulkner, Hannigan, and Gill 2010). In other words, students that achieved a particular Leaving Certificate mathematics grade in any given year of the period 1998-2008 tended to perform at a similar level when completing the UL diagnostic test.

The shift in emphasis from a focus on procedural knowledge in the previous mathematics curricula in Ireland to a focus on problem-solving in practical contexts through the new Project Maths curricula could be a key reason for this decline in basic mathematical skills among beginning undergraduates at UL. Similarly, there has been a shift in emphasis through which greater emphasis is placed on probability and statistics.

As 2014 was the first year that the fully implemented 'Project Maths' curriculum was examined through the Leaving Certificate examinations, the findings presented here raise questions concerning how this new curriculum affects the development of basic mathematical skills of students studying mathematics at secondary level in Ireland. The shift in focus from emphasis on the execution of procedure and algorithms in the previous Senior Cycle mathematics curriculum to applications of mathematics and problem-solving in the new Project Maths curriculum would, according to this data, appear to be negatively affecting students' execution of basic mathematical skills examined through the UL diagnostic test.

The pattern of declining performance over time which has continued in 2014, as outlined in the results section, may be expected as such a pattern of decline was in evidence prior to the introduction of the Project Maths curriculum (Treacy and Faulkner 2015) and does not necessarily indicate a decline in overall mathematical ability of these students. It has been documented that, in some instances, secondary students studying the Project Maths curriculum appear to be successfully drawing together their knowledge across different mathematical topics thus indicating that they are beginning to acquire a deeper understanding of mathematics and how it can be applied (Jeffes et al. 2013). However, the observed declines outlined in this paper is an indicator that execution of the basic mathematical skills may be an emerging issue that needs to be strongly considered so that deficiencies in this element of students' mathematical abilities can be addressed.

Conversely, it must be noted that performance in the modelling question of students who achieved Higher Level B grades in the Leaving Certificate in the UL diagnostic test show significant improvement between 2008 and 2014 (see Table 6). The aforementioned shift in focus to application of mathematics in different contexts would appear to be aiding the modelling capabilities of the students who experienced the 'Project Maths' syllabus at secondary level. However, having stated that, modelling only accounts for one question on this diagnostic test and, as such, has not been examined in great detail through this test.

Analysis of student performance when Leaving Certificate grades are controlled (see Table 6) would indicate that there are a greater number of significant declines in mean performance within the individual mathematical topics the lower the grade achieved at Higher Level in the Leaving Certificate mathematics examinations by the student. This could be an indicator that the level of basic mathematical skills required to achieve a grade $\mathrm{C}$ or a grade D in Higher Level Leaving Certificate mathematics in 2014 are below that which was required in 2008. Further magnifying the importance of this observation is the recognition that students entering UL service 
mathematics modules with particular Leaving Certificate mathematics grades performed to a similar level in the diagnostic test between 1998 and 2008 (Faulkner, Hannigan, and Gill 2010). Grade dilution must be considered in light of these findings as it is clear that the basic mathematical skills required to achieve Higher Level C and D grades in mathematics at Leaving Certificate in 2014 are below that which were required in 2008 .

In contrast, the basic mathematical skills demonstrated by those who achieved a B grade in Higher Level mathematics at Leaving Certificate have not declined significantly between 2008 and 2014 (see Table 2). As such, it would appear that the transition to a new curriculum has not coincided with a marked decline in basic mathematical skills for these students as measured by the UL diagnostic test. This prompts further strong consideration of the trends highlighted in relation to the students that achieved Higher Level $C$ and D grades in mathematics at Leaving Certificate. If the basic mathematical skills of those tested through the UL diagnostic test who have achieved Leaving Certificate mathematics Higher Level B grades have largely been maintained during this curriculum change then one would question why such skills have changed so significantly among those that achieved Higher Level C and D grades in 2014 when compared to the 2008 cohort (see Table 2). This consideration of grade dilution, however, can only be definitively determined through further research specific to this issue on a national scale but the indicators present in the data analysed suggest such a study is warranted.

The authors are also acutely aware of the potential effect that the bonus points being offered for achieving a grade D3 or higher in Leaving Certificate mathematics at Higher Level from 2012 onwards may have had on the performance of students achieving $\mathrm{C}$ and $\mathrm{D}$ grades at this level. Students who may not have had the required level of basic mathematical skills to achieve a grade C or grade D in Leaving Certificate mathematics Higher Level examinations in the years before the introduction of bonus points may have decided to study Leaving Certificate mathematics at Higher Level in order to achieve these bonus points. As a result, upon the introduction of bonus points, there may have been a rise in students who would potentially fail the Leaving Certificate mathematics Higher Level examination thus prompting those marking the examination to adjust the marking system to avoid a greater proportion of failing grades.

The proportion of students opting for the Higher Level mathematics paper at Leaving Certificate increased from $15.8 \%$ in 2011 to $22.1 \%$ in $2012 ; 25.6 \%$ in 2013 ; and $27 \%$ in 2014 (SEC 2014). In the same period, the proportions of students who failed this examination in $2012(2.3 \%), 2013$ (3.3\%), and 2014 (4.2\%) were quite similar to the failure rate in previous years which was typically about $3 \%$ (SEC 2014). Upon examination of these trends, it is reasonable to question why this would occur given that the proportion of students attempting the Higher Level paper had increased so significantly from 2012 onwards and the basic mathematical skills of beginning UL undergraduates, measured subsequently through the UL diagnostic test, had diminished at a significant rate. Again, this is an area which requires further research and investigation.

It must also be noted that the UL diagnostic test predominantly examines students' abilities to execute basic mathematical skills and procedures. Thus, outside of one modelling question, the UL diagnostic test lacks the capacity to specifically establish 
whether or not there have been changes in beginning undergraduates' problem-solving and application skills. As specified previously, the UL diagnostic test indicates that beginning undergraduates' basic mathematical skills underwent a decline during the period 2008-2014. It may be claimed that the reason for this decline is that the time taken previously to focus on these basic mathematical skills in the classroom has been sacrificed in order to place greater focus on improving problem-solving and application skills which the UL diagnostic test does not specifically examine. If such a claim is true, then it must be considered in this instance whether or not the sacrifice of students' ability to execute basic mathematical skills and procedures is justified in order to establish improvements in problem-solving and applications of mathematics. Similarly, if students are to apply their understanding of mathematics then surely they must master the basic skills required to successfully apply this understanding. These are key considerations which may play a significant role in shaping the future of mathematics education in Ireland.

\section{Analysing the impact of mathematics curriculum change}

The results outlined in this article provide an important perspective on the transition that mathematics education has undergone at secondary level in Ireland. However, passing judgement at this point regarding the overall impact of the recently introduced Project Maths curriculum would be premature. Portugal implemented a mathematics curriculum change at secondary level in the early 1990s which was quite similar to the mathematics curriculum change implemented in Ireland recently as greater emphasis was placed on problem-solving, real world applications, and graphical representations (Ponte et al. 1994). Ponte et al. (1994) completed a comprehensive study of the views and attitudes of teachers and students who were involved in a pilot curriculum development programme for this curriculum change. It was determined that the 7 th grade students (12-13-year-olds) displayed the most noticeable change in attitude and a greater willingness to embrace the new approach to mathematics classes. In contrast, the 10th grade students (15-16-year-olds) did make some adjustments but seemed to have established expectations regarding mathematics lessons, rejecting exploratory activities they perceived to be 'distracting and inefficient' (Ponte et al. 1994, 363).

Observations of this nature highlight the difficulties which may be encountered during the initial stages of curriculum change in mathematics at secondary level, thus prompting the authors to suggest that the overall effect of such curriculum change cannot be fully gauged at this early stage. It may be the case that, similar to that which was reported by Ponte et al. (1994), the Project Maths curriculum is being embraced in a more comprehensive manner by younger secondary school students, thus the effects of this change would not be evident at Leaving Certificate or upon their entry to third level education for a number of years. Research has shown that mathematics curriculum reform takes time to fully implement with plenty of obstacles impeding widespread adoption of the ideals espoused (Handal and Herrington 2003; Schoenfeld 2014). As such, the findings discussed in this article need to be carefully considered so that they may inform mathematics teaching and learning at secondary level in Ireland, but must not be interpreted as an outright indictment of the Project Maths curriculum. Judgement of the new curriculum must be reserved until the full impact of this curriculum change can be properly observed in the years to come. 


\section{Conclusion}

The phased introduction of the new Project Maths Senior Cycle curriculum in Ireland aims to place greater emphasis on student understanding of mathematical concepts with increased use of contexts and applications of mathematics in real world scenarios (DES 2010). In addition to this, the introduction of bonus points awarded to students who pass mathematics at Higher Level in the Leaving Certificate examinations has been put in place to encourage a higher proportion of students to study mathematics at this level in upper secondary education in Ireland. The bonus points measure has been successful in so far as there has been a marked increase in the proportions of students studying Higher Level mathematics at Leaving Certificate since its introduction. However, it would appear that, according to the findings outlined in this research, this measure and the new curriculum has coincided with a decline in performance of basic mathematical skills among beginning undergraduate students entering UL from Irish secondary education.

Significant declines in beginning undergraduates' performance of basic mathematical skills are evident, particularly among students who have achieved Higher Level $\mathrm{C}$ grades and Higher Level D grades in mathematics at Leaving Certificate. These declines are especially noticeable in topics such as arithmetic, algebra, geometry, and calculus. Such findings prompt the authors to query whether grade dilution is an emerging issue in relation to grades awarded for Leaving Certificate mathematics examinations. In any case, the noted declines in performance of basic mathematical skills does not bode well for successful transition to study of service mathematics modules at tertiary level and, given that mathematics is the strongest predictor of successful student progression through tertiary level education in Ireland (Mooney et al. 2010), this is an issue which needs to be addressed sooner rather than later.

\section{Notes on contributors}

Dr Páraic Treacy is a lecturer in Teacher education at the University of Derby in the UK. He previously coordinated the Mathematics Learning Centre at the University of Limerick while also assuming the role of lecturer in service mathematics and mathematics pedagogy modules. His research interests include integrating mathematics with other subjects to enhance learning; applications of mathematics; problem-based learning; and student transition from second level mathematics to third level mathematics study.

Dr Fiona Faulkner is a mathematics lecturer on a foundation programme for adult and international students in the Dublin Institute of Technology. Her research interests include Mathematics diagnostic testing; the 'Maths Problem'; out of field teaching and Continuous Professional Development; mathematics education for access, international and engineering students; and teaching Mathematics for Understanding.

Dr Mark Prendergast is an Assistant Professor in Mathematics Education at Trinity College Dublin. His research interests include effective teaching of mathematics; teaching and learning algebra at second level; promoting interest in mathematics; mathematics support for students at third level; the importance of literacy skills in learning mathematics.

\section{ORCID}

Páraic Treacy (D) http://orcid.org/0000-0002-6447-1798

Mark Prendergast (D) http://orcid.org/0000-0002-1766-7421 


\section{References}

Bourn, J. 2007. Staying the Course: The Retention of Students in Higher Education. London: The Stationery Office.

Carr, M., B. Bowe, and E. Ní Fhloinn. 2013. "Core Skills Assessment to Improve Mathematical Competency." European Journal of Engineering Education 38 (6): 608-619. doi:10.1080/ 03043797.2012.755500.

Cleary, J. 2007. "Diagnostic Testing - An Evaluation 1998-2007." In Proceedings of Second National Conference on Research in Mathematics Education (MEI2), edited by S. Close, D. Corcoran, and T. Dooley, 215-227. Dublin: St. Patrick's College.

DES (Department of Education and Skills). 2010. Report of the Project Maths Implementation Support Group. Accessed 5 June 2015. https://www.education.ie/en/Publications/PolicyReports/Report-of-the-Project-Maths-Implementation-Group.pdf.

Faulkner, F. 2012. "An Analysis of Performance in Mathematics for Technology Undergraduates and an Investigation of Teaching Interventions for These Students." PhD diss., University of Limerick.

Faulkner, F., A. Hannigan, and O. Fitzmaurice. 2014. "The Role of Prior Mathematical Experience in Predicting Mathematics Performance in Higher Education." International Journal of Mathematical Education in Science and Technology 45 (5): 648-667. doi:10. 1080/0020739X.2013.868539.

Faulkner, F., A. Hannigan, and O. Gill. 2010. "Trends in the Mathematical Competency of University Entrants in Ireland by Leaving Certificate Mathematics Grade." Teaching Mathematics and Its Applications 29 (2): 76-93. doi:10.1093/teamat/hrq002.

Gill, O., J. O'Donoghue, F. Faulkner, and A. Hannigan. 2010. "Trends in Performance of Science and Technology Students (1997-2008) in Ireland." International Journal of Mathematical Education in Science and Technology 41 (3): 323-339. doi:10.1080/ 00207390903477426.

Handal, B., and A. Herrington. 2003. "Mathematics Teachers' Beliefs and Curriculum Reform." Mathematics Education Research Journal 15 (1): 59-69. doi:10.1007/BF03217369.

Jeffes, J., E. Jones, M. Wilson, E. Lamont, S. Straw, R. Wheater, and A. Dawson. 2013. Research into the Impact of Project Maths on Student Achievement, Learning and Motivation: Final Report. Slough: NFER.

Klein, D. 2007. "A Quarter Century of US 'Math Wars' and Political Partisanship." BSHM Bulletin: Journal of the British Society for the History of Mathematics 22 (1): 22-33. doi:10.1080/17498430601148762.

Koyama, M. 2010. "Mathematics Curriculum in Japan." In Reforms and Issues in School Mathematics in East Asia: Pursuing Excellence in Mathematics Curriculum and Teacher Education, edited by F. K. S. Leung and Y. Li, 59-78. Rotterdam: Sense.

Lawson, D. 2003. "Changes in Student Entry Competencies 1991-2001." Teaching Mathematics and Its Applications 22 (4): 171-175. doi:10.1093/teamat/22.4.171.

Lawson, D., T. Croft, and D. Waller. 2012. "Mathematics Support Past, Present and Future." Paper presented at International Conference on Innovation, Practice and Research in Engineering Education, September 18-20, Coventry University, UK.

Liston, M., and J. O’Donoghue. 2009. "Factors Influencing the Transition to University Service Mathematics: Part 1 a Quantitative Study.” Teaching Mathematics and Its Applications 28 (2): 77-87. doi:10.1093/teamat/hrp006.

Liu, J., and Y. Li. 2010. "Mathematics Curriculum Reform in the Chinese Mainland: Changes and Challenges." In Reforms and Issues in School Mathematics in East Asia: Pursuing Excellence in Mathematics Curriculum and Teacher Education, edited by F. K. S. Leung and Y. Li, 9-31. Rotterdam: Sense.

McCoy, S., E. Smyth, D. Watson, and M. Darmody. 2014. Leaving School in Ireland: A Longitudinal Study of Post-school Transitions. Dublin: ESRI.

Mooney, O., V. Patterson, M. O'Connor, and A. Chantler. 2010. A Study of Progression in Irish Higher Education. Dublin: HEA.

NCCA (National Council for Curriculum and Assessment). 2008. Project Maths - Information for Schools. Accessed 5 June 2015. http://www.ncca.ie/uploadedfiles/mathsreview/pmaths_en. pdf. 
NCCA (National Council for Curriculum and Assessment). 2014. Maths in Practice - Report and Recommendations. Accessed 5 June 2015. http://www.ncca.ie/en/Curriculum_and_ Assessment/Post-Primary_Education/Project_Maths/Information/Reports/Maths-inPractice-Report-.pdf.

Ní Ríordáin, M., and A. Hannigan. 2011. "Who Teaches Mathematics at Second Level in Ireland?" Irish Educational Studies 30 (3): 289-304. doi:10.1080/03323315.2011.569117.

Ni, Y. J., X. Li, D. Zhou, and Q. Li. 2014. "Changes in Instructional Tasks and Their Influence on Classroom Discourse in Reformed Mathematics Classrooms of Chinese Primary Schools." In Transforming Mathematics Instruction, edited by Yeping Li, Edward A. Silver, and Shiqi Li, 217-230. Cham: Springer.

O'Donoghue, J. 2004. "An Irish Perspective on the 'Mathematics Problem."” Plenary Lecture at The Second Irish Symposium for Undergraduate Mathematics Education, December 10-11, Dublin, Ireland.

OECD. 2010. The High Cost of Low Educational Performance. Accessed 5 June 2015. http:// www.oecd-ilibrary.org/docserver/download/9810021e.pdf?expires $=1453213828 \& \mathrm{id}=$ id\&accname $=$ guest $\&$ checksum $=$ 79EB408031D1C645D81F90372ADAC54C.

OECD. 2014. PISA 2012 Results: What Students Know and Can Do-student Performance in Mathematics, Reading and Science. Accessed 5 June 2015. http://www.mecd.gob.es/dctm/ inee/internacional/pisa2012/pisa2012voliinternacional.pdf?documentId=0901e72b8178af63.

Oldham, E. 2001. "The Culture of Mathematics Education in the Republic of Ireland: Keeping the Faith?" Irish Educational Studies 20 (1): 266-277.

Ponte, J. P., J. F. Matos, H. M. Guimarães, L. C. Leal, and A. P. Canavarro. 1994. "Teachers' and Students' Views and Attitudes Towards a New Mathematics Curriculum: A Case Study." Educational Studies in Mathematics 26 (4): 347-365. doi:10.1007/BF01279520.

Schoenfeld, A. H. 2004. "The Math Wars.” Educational Policy 18 (1): 253-286. doi:10.1177/ 0895904803260042.

Schoenfeld, A. H. 2014. "Reflections on Curricular Change." In Mathematics Curriculum in School Education, edited by Yeping Li and Glenda Lappan, 49-72. Dordrecht: Springer.

State Examination Commission (SEC). 2014. State Examination Statistics. Accessed 5 June 2015. https://www.examinations.ie/index.php?1=en\&mc $=$ st\&sc $=r 14$.

Treacy, P., and F. Faulkner. 2015. "Trends in Basic Mathematical Competencies of Beginning Undergraduates in Ireland, 2003-2013." International Journal of Mathematical Education in Science and Technology, Ahead of Print. doi:10.1080/0020739X.2015.1050707.

Van den Heuvel-Panhuizen, M. 2000. Mathematics Education in the Netherlands: A Guided Tour. Utrecht: Freudenthal Institute. CD-ROM.

Van den Heuvel-Panhuizen, M., and P. Drijvers. 2014. "Realistic Mathematics Education." In Encyclopedia of Mathematics Education, edited by Steve Lerman, 521-525. Dordrecht: Springer.

Woodward, J. 2004. "Mathematics Education in the United States Past to Present." Journal of Learning Disabilities 37 (1): 16-31. doi:10.1177/00222194040370010301. 
Appendix 1. Sample of questions from the UL Diagnostic Test

12. Express 0.01234 in Scientific Notation. Ans $\square$ Don't know

13. Divide 30 in the ratio $3: 2$

Ans $\square$ Don't know

\section{ALGEBRA 014-021}

14. Solve for $h: V=\pi r^{2} h$

Ans $\square$ Don't know

15. Evaluate $\mathrm{ab}+2 \mathrm{bc}-3 \mathrm{ac}$ when $a=3, b=-2$ and $c=4$.

Ans $\square$ Don't know

16. Solve the equation: $3(x+2)-24=0$

Ans $\square$ Don't know

17. Solve for $x: x^{2}+x-6=0$

Ans $\square$ Don't know

18. Solve the set of equations:

$$
\begin{aligned}
& 2 x+y=7 \\
& x+2 y=5
\end{aligned}
$$

Ans $\square$ Don't know

19. Write out $(x+3 y)(a-2 b)$ in an equivalent form without brackets.

Ans $\square$ Don't know

20. Solve for $x: 3-6 x<21$

Ans $\square$ Don't know

21. Simplify $\frac{1}{x-1}-\frac{2}{x+1}$

Ans $\square$ Don't know 